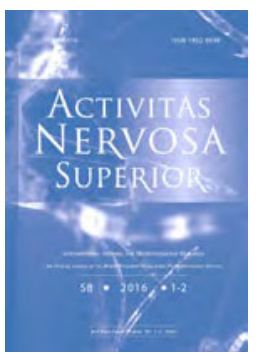

ANS: Journal for Neurocognitive Research Homepage:

WWW.activitas.org

SHORT COMMUNICATION

\title{
Profile of NeUrocognitive FunCtioning IN ADULTS INFECTED WITH HIV
}

\author{
Anindita Mukherjee, Asmita Karmakar*, Payel Dutta, Atanu Kumar Dogra \\ Department of Psychology, University of Calcutta, India
}

\begin{abstract}
Since the very beginning of the course of infection, HIV enters into the CNS and it is reflected through neurological disorders. The aim of this study was to assess and subsequently compare the neurocognitive functioning of treatment-naive adults with HIV Stage I, II \& peer control. Cross-sectional Case-control study design was followed. 22 adults (11 in stage I and 11 in stage II) with HIV infection and 11 adults as matched control were administered various standardised neuropsychological tests assessing cognitive functions like verbal fluency, executive functions, memory and visuo-spatial ability. Data were analysed by computing Kruskal Wallis one way ANOVA by ranks and post-hoc analysis (with the help of Mann Whitney U Test). Results showed that adults with HIV infected had poorer performance on most measures of memory functioning, visuo-spatial ability, verbal fluency and some measures of frontal lobe functioning in comparison to the matched peer control group. Those with stage II HIV had more compromised functions than those in stage I HIV in overall frontal lobe functioning along with inhibitory control, conceptualization, mental flexibility and sensitivity to interference.
\end{abstract}

Key words: HIV; Cognitive functions; Frontal lobe functions; Memory; Neuropsychological assessment

\section{INTRODUCTION}

In the evolutionary process of species, one of the promising achievement of human being is development of higher cognitive functions and it can be defined as cerebral activities that encompass attention and concentration, learning and memorizing, developing and utilizing language and finally, different executive functioning used to the attainment of information. These interdependent, progressively acquired, higher order cognitive functioning are emerged in human being due to development of cerebrum and integrations of cerebellum, subcortical, corticocortical and prefrontal neural network. When structurally or functional network of CNS is affected by any infectious disease, it hampers cognitive and affective functioning. One of the viral infections is human immunodeficiency virus (HIV) which gradually affects holistic immunity capacity and prone the person to acquire different immunodeficiency disorders.

In these connections, neurocognitive and motor dysfunction are commonly seen in HIV infected adult and children along with other immunodeficiency symptoms (Navia, Jordan \& Price, 1986). From the early stage of HIV infection, it affects CNS and generates HIV associated neurological disorders (HAND) and central nervous system opportunistic infections. HAND is a spectrum ranging from mild, clinically asymptomatic neurologic impairment to severe,

*Asmita Karmakar, email: asmitakarmakar91@gmail.com

Received March 20, 2016; accepted June 10, 2016; Act Nerv Super 58(1-2), 20-27; ISSN-1802-9698 
HIV-associated dementia (HAD). HAND represents a syndrome which is characterised as constellation of abnormalities in cognition, motor and behavioral function (Price et al, 1988). In addition to global deficits in cognitive functioning of HIV patients, more specific neuropsychological deficits have been reported, such as executive functioning deficits (Reger et al, 2002), impairments in divided attention (Hinkin et al, 2000), response inhibition (Hinkin et al, 1999) and episodic memory (Heaton et al, 1995; Rippeth et al, 2004).

Although HAND is seen more frequently in people with AIDS (about 50\% of individuals), it also occurs in people with asymptomatic HIV (approximately $30 \%$ of persons) (Heaton et al 1995). Even after establishment and application of highly active antiretroviral therapy as the mainstay of HIV treatment on clients, milder forms of neurocognitive dysfunction are evident. In fact, it may have even increased in individuals who are not immunosuppressed (Nath et al, 2008).

Currently, no single pathophysiological mechanism can explain the cognitive and neurological impairments of HIV and the clinical findings are typically the expression of a diffuse rather than of a focal CNS disorder. HIV invades the brain soon after systemic infection and is commonly found in the cerebro-spinal fluid (CSF) of asymptomatic HIV patients. In some neuroimaging studies, it was reported that HIV interferes with the higher cognitive functioning along with complex executive skills relying on the integration of white matter and of fronto-striatal circuits (Woods et al., 2009).

Since there is dearth of neuropsychological and neuro-imaging studies concerning HIV in our developing country, aim of the study was to evaluate and subsequently compare the status of different specific domains of cognitive functioning of treatment-naive Stage I and Stage II HIV patients, with non-clinical matched peer group.

\section{METHODS}

\subsection{Participants}

The study had two groups of participants matched in terms of age and education: HIVinfected group and non-clinical peer group. In the clinical group, of $22 \mathrm{HIV}$-infected adults 9 males and 13 females) with no history of neurological disease (e.g. seizure disorder), significant developmental problems (e.g. diagnosis of learning disability), CNS opportunistic infection, head trauma with loss of consciousness exceeding 30 minutes, or substance abuse or dependence in the past two months, participated in this study. These 22 participants were divided into subgroups on the basis of their CD4 counts, as per the recent guidelines provided by the Center for Disease Control and Prevention. 11 of the participants, having CD4 counts over 500 were in the Stage I HIV group (Mean CD4 count=630) and the rest 11 of the participants with CD4 counts between 200 and 500 were in the Stage II HIV group (Mean CD4 count=320). None of the participants had AIDS-defining illnesses or CD4 counts less than 200. Participants in each of the subgroups were similar in age (Mean age of participants: Stage I HIV group $=34.4$ years; Stage II HIV group=34.7 years) and education (Mean years of education: Stage I HIV group: 7.3 years; Stage II HIV group: 7.6 years). CD4 counts were significantly different across the two subgroups. All of the participants had acquired HIV horizontally and were treatment-naive. HAM-A and HAM-D were administered to rule out the possibility of presence of anxiety and depression.

The non-clinical peer control group had 11 participants ( 5 males and 6 females), who were matched in terms of age and education (Mean age $=34.9$ years; Mean years of education: 7.4 years). Those having history of any sort of neurological problem or psychiatric problem were excluded. GHQ-12 was administered to rule out psychiatric morbidity. Those scoring above 3 in GHQ-12 were excluded. 


\subsection{Tools}

Following tools were used to assess the neurocognitive functioning of the sample:

Animal naming test (Lezak, 1995) assesses verbal categorical fluency which is a measure of how quickly and efficiently a person can access stored knowledge about words. It evaluates an individual's ability to retrieve specific information within restricted search parameters (Lezak, Howieson \& Loring, 2004).

The Frontal Assessment Battery (Dubois, Slachevsky, Litvan and Pillon, 2000) has six subtests that evaluate both cognitive and behavioural function of the prefrontal lobe, including categorization, sensitivity to interference, inhibition of response etc.

The Clock-drawing test used to assess visuo-constructional ability of the patient. In this study, the scoring was done using the method developed by Sunderland and Colleagues (Sunderland et al, 1989).

PGIMS (Pershad \& Wig, 1976) is an Indian adaptation of the Wechsler Memory Scale. It consists of 10 subtests ( 9 Verbal and 1 nonverbal). It measures remote memory, recent memory, mental balance, attention and concentration, delayed recall, immediate recall, retention for similar pairs, retention for dissimilar pairs, visual retention and recognition.

\subsection{Procedure}

Recruitment for testing, scheduling and testing was done by an experienced psychologist during the participant's visit to a Secondary care hospital for clinical examination, after obtaining informed consent. Complete testing was done in two separate sessions that were separated by a $30-45$ minutes break. In all the cases, testing was completed on the same day. Testing was done prior to exposure to Antiretroviral therapy.

\subsection{Data analysis}

Analysis of the data was done in two phases. In the first phase, since the data did not meet the criteria for parametric tests, non-parametric Kruskal Wallis test was done to observe if there was significant mean difference between the three groups i.e. Stage I HIV group, Stage II HIV group and non-clinical peer group with respect to their scores on different domains of cognitive functions as assessed by afore said neuropsychological tests. In the second phase, for the domains of cognitive functions on which significant mean difference was observed, MannWhitney U was as a post hoc analysis. All Data analyses were done using SPSS (Statistical Package for Social Sciences) version 16.

\section{RESULTS}

Results (Table 1) show that in case of memory functioning, remote memory (here ability to recall autobiographical events of the past), recent memory (ability to remember relatively new episodic incidents in life), Attention and concentration (as a part of executive functioning) and immediate verbal recall (verbal working memory as a function of prefrontal cortex) and Delayed recall (reflection of memory consolidation process) were found to be compromised in adults suffering from HIV. These memory functioning profiles are relatively more impaired in Stage II HIV than those in stage I HIV group and controls respectively. 
Table 1. Table showing the Mean scores of each groups and significance of difference between means as well as results of Post Hoc analysis.

\begin{tabular}{|c|c|c|c|c|c|c|}
\hline \multirow[t]{2}{*}{ Test } & & \multicolumn{3}{|c|}{ Mean score } & \multirow[b]{2}{*}{$\mathrm{H}$ value } & \multirow[b]{2}{*}{ Post Hoc } \\
\hline & & $\begin{array}{l}\text { Non } \\
\text { clinical } \\
\text { Gr. }\end{array}$ & $\begin{array}{l}\text { HIV Gr } \\
\text { I }\end{array}$ & $\begin{array}{l}\text { HIV } \\
\text { Gr II }\end{array}$ & & \\
\hline \multirow{11}{*}{ PGIMS } & Remote & 4.36 & 2.43 & 1.15 & $8.36^{*}$ & $\mathrm{~A}, \mathrm{~B}, \mathrm{C}$ \\
\hline & Recent & 4.18 & 2.45 & 3.45 & $12.45^{*}$ & $\mathrm{~A}, \mathrm{C}$ \\
\hline & Mental balance & 3.82 & 1.18 & 1.2 & 5.04 & - \\
\hline & $\begin{array}{l}\text { Attention \& } \\
\text { concentration }\end{array}$ & 4.27 & 3.02 & 1.34 & $13.86^{*}$ & $\mathrm{~B}, \mathrm{C}$ \\
\hline & Delayed recall & 3.09 & 1 & 0.45 & $6.685^{*}$ & $\mathrm{~A}, \mathrm{~B}, \mathrm{C}$ \\
\hline & $\begin{array}{l}\text { Immediate } \\
\text { recall }\end{array}$ & 4 & 1.64 & 1.09 & $8.15^{*}$ & $\mathrm{~A}, \mathrm{C}$ \\
\hline & $\begin{array}{l}\text { Verbal } \\
\text { retention for } \\
\text { similar pair }\end{array}$ & 4.09 & 2.73 & 2.64 & 5.01 & - \\
\hline & $\begin{array}{l}\text { Verbal } \\
\text { retention for } \\
\text { dissimilar pair }\end{array}$ & 4.45 & 2.72 & 2.9 & 4.08 & - \\
\hline & $\begin{array}{l}\text { Visual } \\
\text { Retention } \\
\end{array}$ & 4.65 & 4.56 & 3.96 & 3.08 & - \\
\hline & $\begin{array}{l}\text { Visual } \\
\text { Recognition }\end{array}$ & 4.87 & 4.32 & 4.01 & 3.28 & - \\
\hline & Total & 32.26 & 17.17 & 14.24 & $20.09^{*}$ & $\mathrm{~A}, \mathrm{C}$ \\
\hline $\begin{array}{l}\text { Visuo- } \\
\text { spatial } \\
\text { ability }\end{array}$ & & 3 & 1.9 & 0.82 & $11.01^{*}$ & $\mathrm{C}$ \\
\hline $\begin{array}{l}\text { Animal } \\
\text { naming }\end{array}$ & & 15 & 11.27 & 8.82 & $12.39^{*}$ & $\mathrm{~A}, \mathrm{~B}, \mathrm{C}$ \\
\hline \multirow{7}{*}{ FAB } & $\begin{array}{l}\text { Conceptualisati } \\
\text { on }\end{array}$ & 2.73 & 1.98 & 1.27 & $6.95^{*}$ & $\mathrm{C}$ \\
\hline & $\begin{array}{l}\text { Mental } \\
\text { flexibility }\end{array}$ & 2.18 & 1.82 & 0.73 & $5.98^{*}$ & $\mathrm{~B}, \mathrm{C}$ \\
\hline & Programming & 2.54 & 2.57 & 1.36 & 4.01 & - \\
\hline & $\begin{array}{l}\text { Sensitivity to } \\
\text { interference }\end{array}$ & 2.73 & 1.66 & 0.36 & $5.65^{*}$ & $\mathrm{~B}, \mathrm{C}$ \\
\hline & $\begin{array}{l}\text { Inhibitory } \\
\text { control }\end{array}$ & 2.45 & 2.36 & 0.82 & $5.41^{*}$ & $\mathrm{C}$ \\
\hline & $\begin{array}{l}\text { Environmental } \\
\text { autonomy }\end{array}$ & 2.91 & 2.01 & 2.45 & 5.63 & - \\
\hline & Total & 15.55 & 12.21 & 7 & $10.23^{*}$ & $\mathrm{~B}, \mathrm{C}$ \\
\hline
\end{tabular}

Note. ${ }^{*}=$ significant at 0.05 level,

$\mathrm{H}=$ Mean difference computed by Kruskal Wallis One Way ANOVA,

$\mathrm{A}=$ Significant mean difference between Non-clinical group and Stage I HIV group.

$\mathrm{B}=$ Significant mean difference between Stage I HIV group and Stage II HIV group.

$\mathrm{C}=$ Significant mean difference between Non-clinical group and Stage II HIV group. 


\section{DISCUSSION}

The aim of this study was to investigate the neurocognitive functioning of treatment-naive adults with HIV in comparison to non-clinical adults.

Earlier studies (Heaton et al, 1995; Rippeth et al 2004; Carey et al, 2004) reported impaired memory functioning in HIV infected adults and thus are consistent with our findings. Studies by Becker et al (1995), Delis et al (1995) found that approximately 30-40\% of HIV infected persons show disturbances in immediate and delayed free recall. Reger et al (2002), Brew (2004) found attention and concentration skills to be relatively spared in early stages of HIV infection, but to be moderately impaired on later stages. Gongvatana et al (2007) found poorer recall in adults with HIV and this impairment to increase in magnitude with the severity of HAND.

In clock drawing test, visuo-spatial and visuo-constructional abilities are mostly used (Bettersby et al., 1956) along with receptive language, numerical knowledge, working memory and executive functioning (Motor and cognitive) (Lezak,1995). Stage II HIV group was found to have poorer visuo-spatial and visuo-constructional ability than non-clinical group. It might be inferred from the study that spatial cognition is affected in later stage of HIV infection. Although the result of this study is not consistent with the few previous finding that spatial cognition is largely unaffected by HIV infection (Heaton et al, 1995); it might have occurred due to involvement of visuo constructional ability, in which fronto-striato-parietal network might be involved.

Indeed, a few small early studies of HIV infection revealed evidence of possible mild deficits in spatial cognition, including visuo-construction and visuo-spatial skills (Poutiainen et al 1988). Also, recent meta-analyses of these early data have shown mixed results (Reger et al 2002; Cysique et al 2006). Although these studies substantiate the likelihood that subtle deficits exist in visuo-perceptual skill in HIV infection, the underlying etiology is still not clear. However, multidisciplinary and micro-scale investigations of spatial cognition in HIV would be needed to elucidate the origin of impairment.

Verbal fluency is a measure of an individual's ability to retrieve specific concept within restricted search parameters. It requires executive control over cognitive processes such as selective attention, selective inhibition, mental set shifting, switching, internal response generation and self monitoring. Both Stage I and Stage II HIV group had poorer verbal fluency than non-clinical group and those in stage II HIV had the least degree of fluency. Studies by Rippeth et al (2004), McCabe et al. (2007) found reduced verbal fluency in HIV and thus supports our findings. Iudicello et al. (2007) found verbal fluency deficits to be mild at initial stage but to increase to moderate with progression of HIV infection.

Noun generation is posited to rely primarily on temporo-parietal networks and semantic memory stores. Prior neuroimaging research has shown that verbal fluency deficits correlate with neurodegeneration in fronto-striatal systems (Hestad et al, 1993). But, the association between switching and measures of verbal fluency, involvement of semantic memory, consistent with modern conceptualisation of verbal fluency suggests a possible involvement of frontotemporal networks too. Both functional and structural neuroimaging studies are needed to clarify these neural underpinnings.

Overall frontal lobe functioning along with inhibitory control, conceptualization, mental flexibility and sensitivity to interference was found to be affected in Stage II HIV Group. However, no relative impairment was found in HIV Stage I Group. Domain of environmental autonomy was found to be spared in both HIV Groups.

Frontal lobe functions like conceptualization, mental flexibility, sensitivity to interference, inhibitory control require abstract reasoning, ability to formulate self-organised cognitive strategies, behavioural self-regulation and ability withhold a spontaneous response. These functions are intricately intertwined with executive functions, which include complex problem-solving abilities, self-directed independent behaviours, and set-shifting functions 
among other abilities (Mega \& Cummings, 1994). Intact executive functions are most notably dependant on the frontal cortex (Specifically the Dorsolateral Prefrontal Cortex, orbitofrontal pre frontal and ventro medial prefrontal cortex), as well as Basal Ganglia (Stuss \& Levine, 2002). It is widely held that HIV is associated with executive dysfunctions, especially in the later stages of the disease (Reger et al, 2002). In fact, executive dysfunction is central to most HIV neurocognitive impairment profiles (Dawes et al, 2008). Morphometric analysis, using MRI has shown decreased volume of basal ganglia in advanced HIV disease (Jernigan et al, 1993). Recent studies have reported more specific findings like impairments in response inhibition and sensitivity to interference (Hinkin et al, 1999; Tozzi et al, 1999), cognitive planning (Bartok et al, 1997), abstraction (Heaton et al, 1995). As compared with other ability areas, like memory, learning, relatively fewer studies have studied the underlying pathophysiological and cognitive processes of executive and different specific frontal lobe functioning deficits in HIV. More elaborate studies combining newer conceptual aspects of executive functions and frontal lobe functions and their intersection might be of great importance.

This study has a number of limitations that need to be considered while interpreting the findings. Given the limited sample size and cross-sectional design of the study, the investigation of profile of different neurocognitive functions represents only a limited exploration. A study with bigger sample size, examining the predictive value of CD4 cell counts in neurocognitive functioning would be beneficial. Although several neurocognitive domains were investigated in this study, a more exhaustive test battery assessing language capabilities more extensively would be needed in future research, because speech and language are considered fundamental in daily living.

This study elucidates the nature and extent of impairment of different cognitive functions in treatment-naive HIV infected adults. This study also supports the idea that evaluation of specific and subtle aspects of neurocognitive functioning may be more sensitive in monitoring the degree of neurocognitive impairment in HIV disease. The findings of this study that subtle neurocognitive impairment may be present despite early stage of the disease and clinically asymptotic status and high CD4 counts, indicate that screening for HAND should become an important part of an initial assessment. The possibility of neurocognitive impairment should be screened upon entry to care. Patients who have a low CD4 count, should be screened more frequently.

\section{REFERENCES}

Bartok, J. A., Martin, E. M., Pitrak, D. L., Novak, R. M., Pursell, K. J., Mullane, K. M., et al. (1997). Working memory deficits in HIVseropositive drug users. Journal of the International Neuropsychological Society, 3, 451-456.

Battersby, W. S., Bender, M. B., Pollack, M., \& Kahn, R. L. (1956). Unilateral “spatial agnosia" ("inattention") in patients with cerebral lesions.Brain, 79, 68-93.

Becker, J. T., Caldararo, R., Lopez, O. L., Dew, M. A., Dorst, S. K., \& Banks, G. (1995). Qualitative features of the memory deficit associated with HIV infection and AIDS: cross-validation of a discriminant function classification scheme. Journal of Clinical and Experimental Neuropsychology, 17, 134-142.

Brew, B. J. (2004). Evidence for a change in AIDS dementia complex in the era of highly active antiretroviral therapy and the possibility of new forms of AIDS dementia complex. AIDS, 18 (Suppl 1), S75-S78.

Carey, C. L., Woods, S. P., Rippeth, J. D., Gonzalez, R., Moore, D. J., Marcotte, T. D., et al. (2004). Initial validation of a screening battery for the detection of HIV-associated cognitive impairment. The Clinical Neuropsychologist, 18, 234-248.

Cysique, L. A., Jin, H., Franklin, D. R., Jr., Morgan, E. E., Shi, C., Yu, X., et al. (2007). Neurobehavioral effects of HIV-1 infection in China and the United States: a pilot study. Journal of the International Neuropsychological Society, 13, 781-790. 
Dawes, S., Suarez, P., Casey, C. Y., Cherner, M., Marcotte, T. D., Letendre, S., et al. (2008). Variable patterns of neuropsychological performance in HIV-1 infection. Journal of Clinical and Experimental Neuropsychology, 30, 613-626.

Delis, D. C., Peavy, G., Heaton, R., Butters, N., Salmon, D. P., Taylor, M., et al. (1995). Do patients with HIV-associated minor cognitive/ motor disorder exhibit a 'subcortical' memory profile? Evidence using the California verbal learning test. Assessment, 2, 151-165.

Dubois, B., Slachevsky, A., Litvan, I., \& Pillon, B.F.A.B (2000). The FAB A frontal assessment battery at bedside. Neurology, 55, 1621-1626.

Gongvatana, A., Woods, S. P., Taylor, M. J., Vigil, O., Grant, I., \& The HNRC Group. (2007b). Semantic clustering inefficiency in HIV-associated dementia. Journal of Neuropsychiatry and Clinical Neurosciences, 19, 36-42.

Heaton, R. K., Grant, I., Butters, N., White, D. A., Kirson, D., Atkinson, J. H., et al. (1995). The HNRC $500-$ Neuropsychology of HIV infection at different disease stages. Journal of the International Neuropsychological Society, 1, 231-251.

Hestad, K., McArthur, J. H., Dal Pan, G. J., Selnes, O. A., Nance- Sproson, T. E., Aylward, E., et al. (1993). Regional brain atrophy in HIV-1 infection: association with specific neuropsychological test performance. Acta Neurologica Scandinavica, 88, 112-118.

Hinkin, C. H., Castellon, S. A., \& Hardy, D. J. (2000). Dual task performance in HIV-1 infection. Journal of Clinical and Experimental Neuropsychology, 22, 16-24.

Hinkin, C. H., Castellon, S. A., Hardy, D. J., Granholm, E., \& Siegle, G. (1999). Computerized and traditional stroop task dysfunction in HIV-1 infection. Neuropsychology, 13, 306-316.

Iudicello, J. E., Woods, S. P., Weber, E., Dawson, M. S., Scott, J. C., Carey, C. L., et al. (2008). Cognitive mechanisms of switching in HIV-associated category fluency deficits. Journal of Clinical and Experimental Neuropsychology, 30, 797-804.

Jernigan, T. L., Archibald, S., Hesselink, J. R., Atkinson, J. H., Velin, R. A., McCutchan, J. A., et al. (1993). Magnetic resonance imaging morphometric analysis of cerebral volume loss in human immunodeficiency virus infection. Archives of Neurology, 50, 250-255.

Lezak, M. (1995). Neuropsychological assessment, 3rd ed. Oxford University Press: New York.

Lezak, M.D., Howieson, D.B., \& Loring, D.W. (2004) Neuropsychological Assesment (Fourth Edition). New York, Oxford University Press.

McCabe, P., Sheard, C., \& Code, C. (2007). Pragmatic skills in people with HIV/AIDS. Disability and Rehabilitation, 29, 1251-1260.

Mega, M. S., \& Cummings, J. L. (1994). Frontal-subcortical circuits and neuropsychiatric disorders. Journal of Neuropsychiatry and Clinical Neuroscience, 6, 358-370.

Nath, A., Schiess, N., Venkatesan, A, Rumbaugh, J, Sacktor, N, \& Mcarthur, J. (2008). Evolution of HIV dementia with HIV infection. International Review of Psychiatry, 20, 25-31

Navia, B.A., Jordan, B.D., \& Price, R.W. (1986). The AIDS dementia complex: I. Clinical features. Annals of Neurology, 19, 517-24.

Pershad, D., \& Wig, N.N (1976) A battery of simple tests of memory for use in India. Neurology India, 24, 86-93.

Poutiainen, E., Iivanainen, M., Elovaara, I., Valle, S. L., \& Lähdevirta, J. (1988). Cognitive changes as early signs of HIV infection. Acta Neurologica, 78, 49-52.

Price, R.W., Brew, B., Sidtis, J., Rosenblum, M., Scheck, A.C., Cleary, P. (1988) The brain in AIDS: central nervous system HIV-1 infection and AIDS dementia complex. Science, 239, 586-92.

Reger, M., Welsh, R., Razani, J., Martin, D. J., \& Boone, K. B. (2002). A meta-analysis of the neuropsychological sequelae of HIV infection. Journal of the International Neuropsychological Society, 8 , 410-424.

Rippeth, J. D., Heaton, R. K., Carey, C. L., Marcotte, T. D., Moore, D. J., Gonzalez, R., et al. (2004). Methamphetamine dependence increases risk of neuropsychological impairment in HIV infected persons. Journal of the International Neuropsychological Society, 10, 1-14. 
Stuss, D. T., \& Levine, B. (2002). Adult clinical neuropsychology: lessons from studies of the frontal lobes. Annual Review of Psychology, 53, 401-433.

Sunderland, T., Hill, J.L., Mellow A.M., Lawlor B.A., Gundersheimer, J., Newhouse, p.A \& Grafman, J.H (1989). Clock drawing in Alzheimer's disease. Journal of the American Geriatrics Society, 37, 725-729

Tozzi, V., Balestra, P., Galgani, S., Narciso, P., Ferri, F., Sebastiani, G., et al. (1999). Positive and sustained effects of highly active antiretroviral therapy on HIV-1-associated neurocognitive impairment. AIDS, 13, 1889-1897.

Woods, S. P., Moore, D. J., Weber, E., \& Grant, I. (2009). Cognitive neuropsychology of HIV-associated neurocognitive disorders. Neuropsychology Review, 19, 152-168. 